\title{
ESTABLISHMENT OF CHEMICAL PREPARATION METHODS AND DEVELOPMENT OF AN AUTOMATED REDUCTION SYSTEM FOR AMS SAMPLE PREPARATION AT KIGAM
}

\author{
Wan Hong ${ }^{1}$ Jung Hun Park $•$ Kyeong J Kim $\bullet$ Hyung Joo Woo $•$ Jun Kon Kim $\bullet$ Han Woo Choi $\bullet$ \\ Gi Dong Kim \\ Korea Institute of Geoscience \& Mineral Resources (KIGAM), 92 Gwahang-no, Yuseong-gu, Daejeon 305-350, Republic of
} Korea.

\begin{abstract}
Many previous studies on the sample preparation of various kinds of radiocarbon dating samples by accelerator mass spectrometry (AMS) have been examined at KIGAM (Korea Institute of Geoscience and Mineral Resources) and our own procedures have been established. Furthermore, an automated reduction system has been developed. The volume of the reduction region was minimized to improve the reduction yield, and air-actuated pneumatic valves and solenoid arrays were used for computer control of the system. Operation of all the valves and vacuum pumps and signals from the temperature sensors and pressure gauges were interfaced to a personal computer with an A/D board. A computer program was also developed to perform automatic operation of the reduction system. This system consistently shows a higher reduction yield than $90 \%$. The reduction time of the system is currently $140 \mathrm{~min}$.
\end{abstract}

\section{INTRODUCTION}

Many sample preparation techniques have been developed by preceding groups since accelerator mass spectrometry (AMS) began to be applied to radiocarbon dating in the 1970s. The KIGAM (Korea Institute of Geoscience and Mineral Resources) AMS group has set up chemical preparation procedures for various kinds of samples by referring to the previous works of the last 4 yr. Because the demand for analyzing soil samples is high in our institute, extra effort was put into soil sample pretreatment method development.

Since an automatic combustion technique using a commercial elemental analyzer (EA) was developed by Aerts-Bijma et al. (1997), many AMS laboratories have used this method to combust samples automatically. Recently, the Erlangen group and ETH group have developed automatic reduction systems coupled with an EA and automated reduction lines. Since 2005, an automated reduction system has also been developed at KIGAM in order to install a ${ }^{14} \mathrm{C}$ dating laboratory. A 1MV AMS system was installed in 2007 at KIGAM (details are described in Hong et al. 2010). The automatic and compact reduction system is critical for the KIGAM AMS laboratory because we have only 2 permanent staff members and 2 temporary staff members for sample preparation and AMS operation, and the space to install the AMS machine and all the chemical and physical preparation facilities is also limited.

In the first stage of the development, a prototype reduction system, which is a semi-automated system, was manufactured to collect basic data to design an automatic system. In 2008, a 24-fold reduction system coupled with an EA was developed. This paper reports specifications of the reduction system and preliminary results of the test run.

\section{CHEMICAL PREPARATION}

Since this is the first report of our sample pretreatment procedures and they are very common methods, only a brief summary was presented here. Wood samples are cut into around 100 mesh pieces.

\footnotetext{
${ }^{1}$ Corresponding author. Email: whong@kigam.re.kr.
}

(C) 2010 by the Arizona Board of Regents on behalf of the University of Arizona Proceedings of the 20th International Radiocarbon Conference, edited by A J T Jull RADIOCARBON, Vol 52, Nr 2-3, 2010, p 1277-1287 
Currently, a ball mill with a zircon jar and balls is tested at our laboratory for the sample grinding. An ABA procedure based on the method of Lee et al. (2000) is used for conventional analysis at our laboratory. For the precise measurement of wood samples, the alpha cellulose extraction procedure (Hua et al. 2000) is employed.

For each shell sample, the surface treatment was performed using a combination of acid, ultrasonic cleaning, and sandblasting methods. Dissolved inorganic carbon (DIC) is treated by the same method as Sveinbjörnsdóttir et al. (1995). Two methods, direct combustion and hydrolysis, are used to convert carbonates to $\mathrm{CO}_{2}$. For routine analysis of calcium carbonates, samples are directly combusted by an $\mathrm{EA}$ at $950^{\circ} \mathrm{C}$. However, $\mathrm{CaCO}_{3}$ samples older than 30,000 yr are converted to $\mathrm{CO}_{2}$ by hydrolysis with $86 \% \mathrm{H}_{2} \mathrm{PO}_{3}$ because the background of the hydrolysis method ( $0.05 \mathrm{pMC}$ ) was found to be lower than the direct combustion method $(0.1 \mathrm{pMC})$ in our previous work with IAEA C1 standard samples (Park et al. 2010). $\mathrm{BaCO}_{3}$ from DIC also should be treated by hydrolysis because it is hard to thermally decompound unlike $\mathrm{CaCO}_{3}$. A carbonate preparation line was designed and structured for hydrolysis, which is similar to the carbonate system presented in Tisnérat-Laborde et al. (2001). The recovery yield of this system was found to be approximately $90 \%$, and the typical vacuum condition is $3 \times 10^{-6}$ Torr. For routine work, $12 \mathrm{mg}$ of carbonates are converted to 120 mTorr of $\mathrm{CO}_{2}$ after purifying, which is calculated to $\sim 1 \mathrm{mg}$ of carbon. $\mathrm{CO}_{2}$ gas is cryogenically transferred to a removable container to transfer to a reduction system.

Although accuracy of dating results for soil-related carbon has been discussed, the dating of organic carbon in soil is very important for us because $90 \%$ of all samples run at KIGAM are soil samples. Three fractions of organics (humin, humic and fulvic acids) in soil are separated by the ABA procedure, and a humic fraction is measured for age dating. Our method for soil preparation is based on the procedure of Kristiansen et al. (2003), but replacing stirring with the ultrasonic method. The advantages of the ultrasonic method are 1 ) higher recovery yield of humic acid by 3-10 times so that soil samples with low carbon content can be measured, and 2) no scratches on glassware containers (beaker or test tube) so that chance of contamination by container material decreases. The details of comparison between stirring and ultrasonic extractions were published in Park et al. (2009).

Our procedure for bone sample treatment is mainly based on the Oxford University method (Jacobi et al. 2006). Using a Vivaspin filter, collagen over $30 \mathrm{kD}$ is selectively collected to remove seriously degraded molecules, and then freeze-dried.

All the experimental conditions and results from the chemical process to AMS measurement are stored semi-automatically to a database system coded by Oracle ${ }^{\mathrm{TM}}$ so that the data can be accessed any time it is needed in the laboratory.

\section{REDUCTION SYSTEM}

A 5-fold semi-automated reduction system, which is a prototype for a fully automated system, was developed to collect basic data for designing a final system. Figure 1a shows a drawing of the reduction region of the semi-automated reduction system, and Figure $1 \mathrm{~b}$ presents the whole reduction system coupled to an elemental analyzer (EA). A furnace made of a silver ingot was developed to heat 5 reduction tubes without the large temperature differences with simple electronics. Water trapping is carried out by an ethanol circulation system that can cool down ethanol to $-70{ }^{\circ} \mathrm{C}$. The reduction system is coupled with an EA (EA1112 CN, Thermo Electron Co.) to combust samples, so that $\mathrm{CO}_{2}$ from EA is directly transferred at a cryogenic trap of a reduction line. The typical vacuum condition of this system is $3 \times 10^{-7}$ Torr in the main vacuum line. 


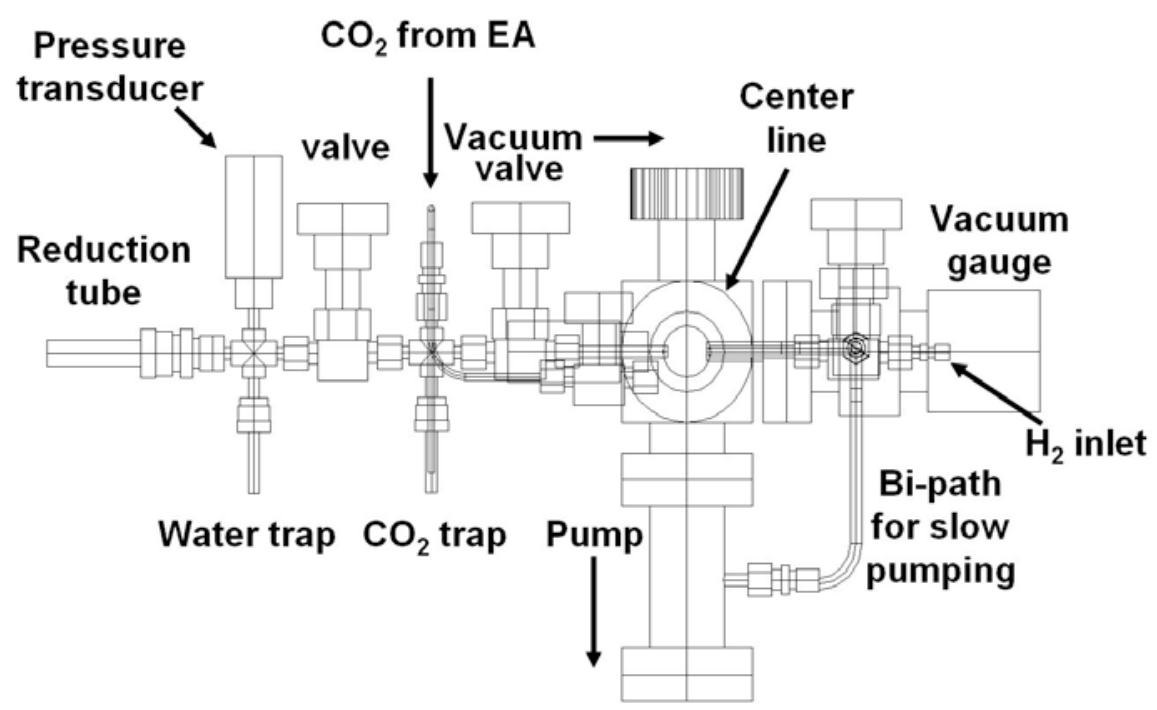

(a)

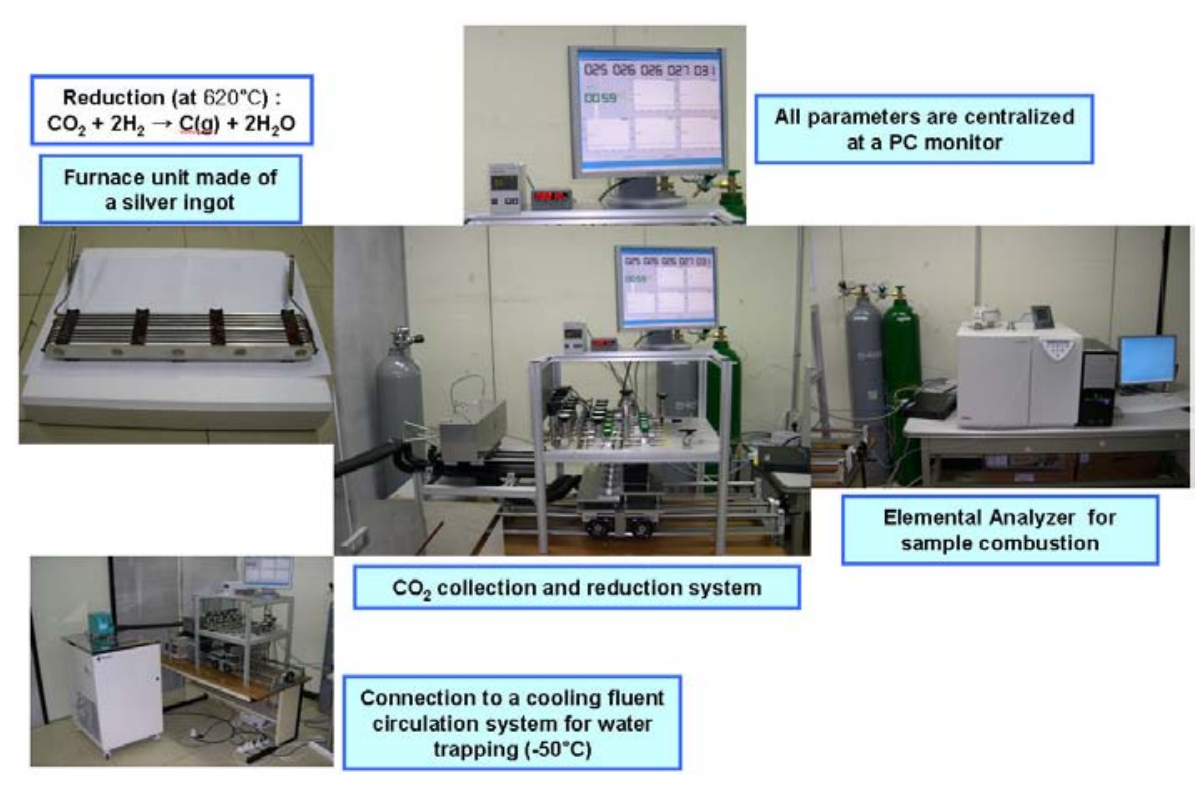

(b)

Figure 1 Layout of the semi-automatic reduction system (prototype): (a) schematic of reduction tube parts; (b) overview of the whole system.

Four mg of Fe catalyst is preheated twice at $500{ }^{\circ} \mathrm{C}$ for $20 \mathrm{~min}$ in an $\mathrm{O}_{2}$ atmosphere to remove contamination and in $\mathrm{H}_{2}$ to reduce the catalyst again. The combustion time is $10 \mathrm{~s}$, and the collection time at a trap is $5 \mathrm{~min}$ for each sample. Every sample combustion is followed by the combustion of an empty tin foil to confirm that $\mathrm{CO}_{2}$ is not detected by the EA any more, which means the previous sample combusted completely. $\mathrm{CO}_{2}$ is moved to a cold finger close to the reduction tube, and the sample size is measured by a pressure gauge. One mg of carbon is used for routine analysis at 
KIGAM. Then, a proper amount of $\mathrm{H}_{2}$ is inserted in the reduction region. As shown in Figure 2, the optimum condition of $\mathrm{CO}_{2} / \mathrm{H}_{2}$ ratio was found to be 1:2.1 for our system. The typical reduction time is $140-160 \mathrm{~min}$ and the temperature is kept at $630{ }^{\circ} \mathrm{C}$. During the reduction, water is trapped via a $-50{ }^{\circ} \mathrm{C}$ ethanol trap. The reduction yield is around $85-98 \%$. Variations of pressure and temperature during the reduction reaction are automatically monitored by a personal computer and displayed at a PC monitor in real time. Figure 3a shows the curves of pressure and temperature changes during the reduction. The reduction is completed within $\sim 140 \mathrm{~min}$. The computer judges the end of the reduction process of each line when 1 of 2 conditions is satisfied: 1 ) the pressure drops below 50 Torr or 2) the pressure change for $10 \mathrm{~min}$ is smaller than 5 Torr. When all the lines satisfy the ending condition, then the reduction is stopped automatically by the PC. The temperature deviation between lines is within $20^{\circ} \mathrm{C}$, and the pressure change curves of each line have very similar shapes to each other.

The reduction yield distribution in 2008 is shown in Figure 3b. These values are overestimated by $3-5 \%$ due to uncertainty of initial $\mathrm{CO}_{2}$ pressures read by pressure gauges. At the beginning of the operation, the yields converged at $95 \%$. However, the yields increased slowly along with time because the initial carbon was underestimated due to the uncertainty of the pressure reading. We found that frequent calibration of each pressure gauge is needed to get precise reduction yield. Values lower than $80 \%$ were measured in the case of a small sample size. For the reduction of smallsized samples, further study and modification of the system is needed. Figure 4 shows the reproducibility and stability of the prototype reduction system. The standard deviation $(1 \sigma)$ of 200 oxalic acid samples (NIST oxalic acid II) in 2008 was found to be $3.2 \%$ of their average value. The average ${ }^{14} \mathrm{C} /{ }^{12} \mathrm{C}$ ratio of 120 blank samples, $3.82 \times 10^{-15}$, is reasonably small. The accuracy of this reduction system was proved by an interlaboratory comparison (see Hong et al. 2010).

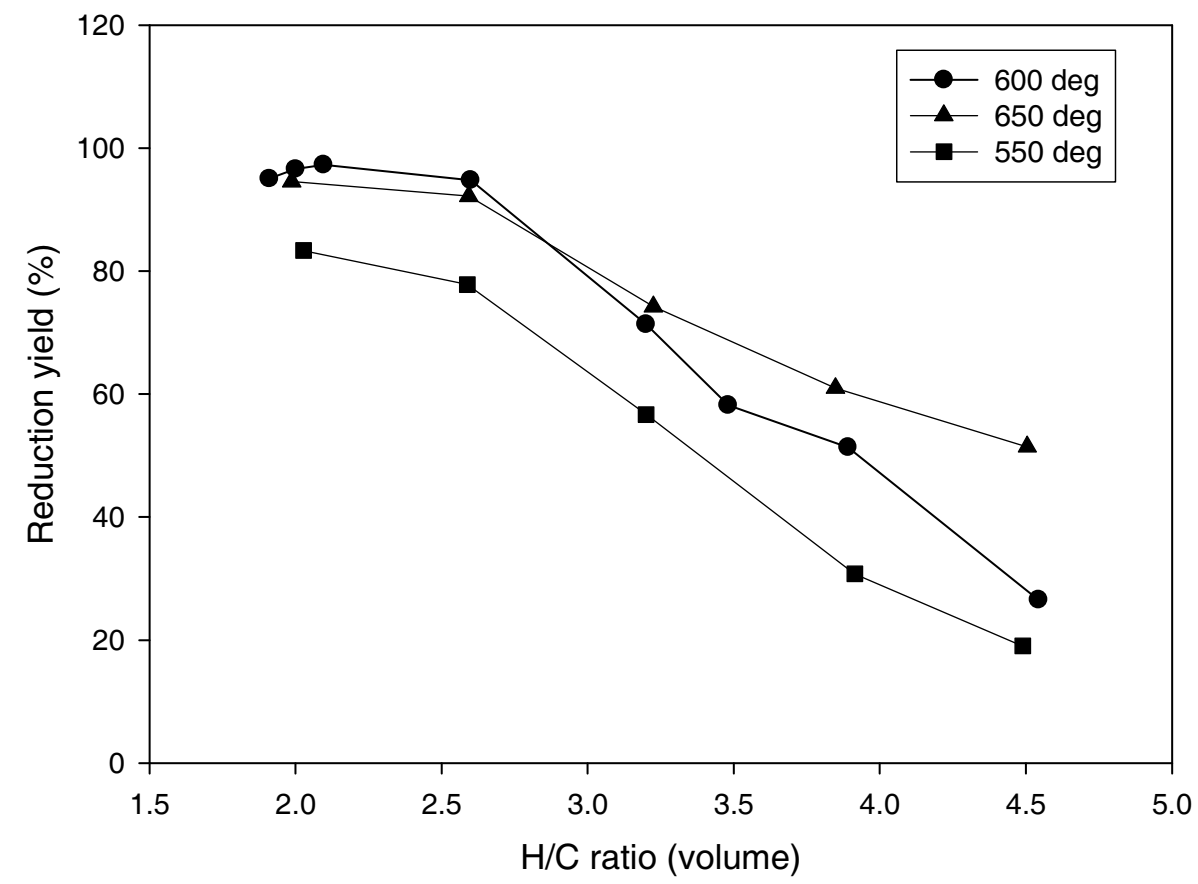

Figure 2 Reduction yield variation along with mixing ratio of $\mathrm{H}_{2} / \mathrm{CO}_{2}$ obtained by the prototype reduction system. 


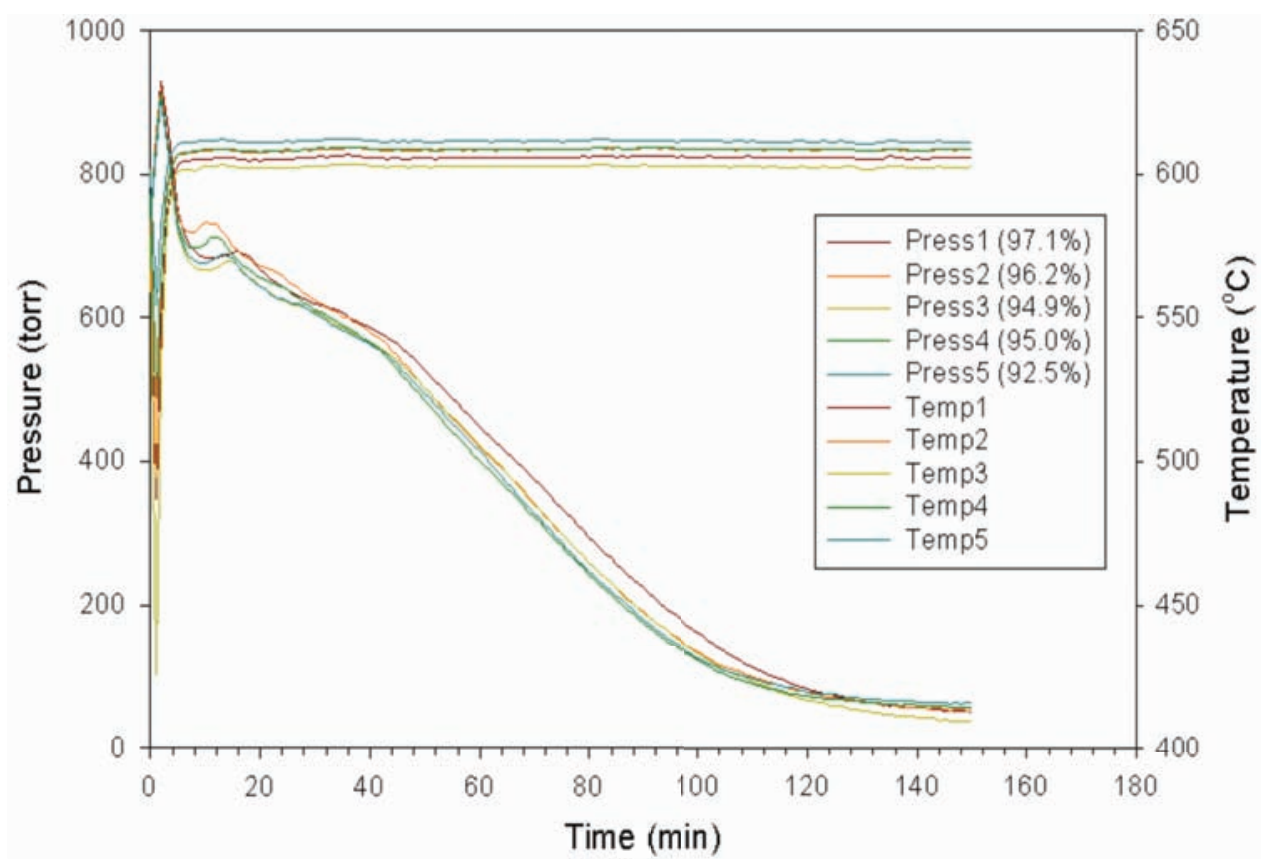

(a)

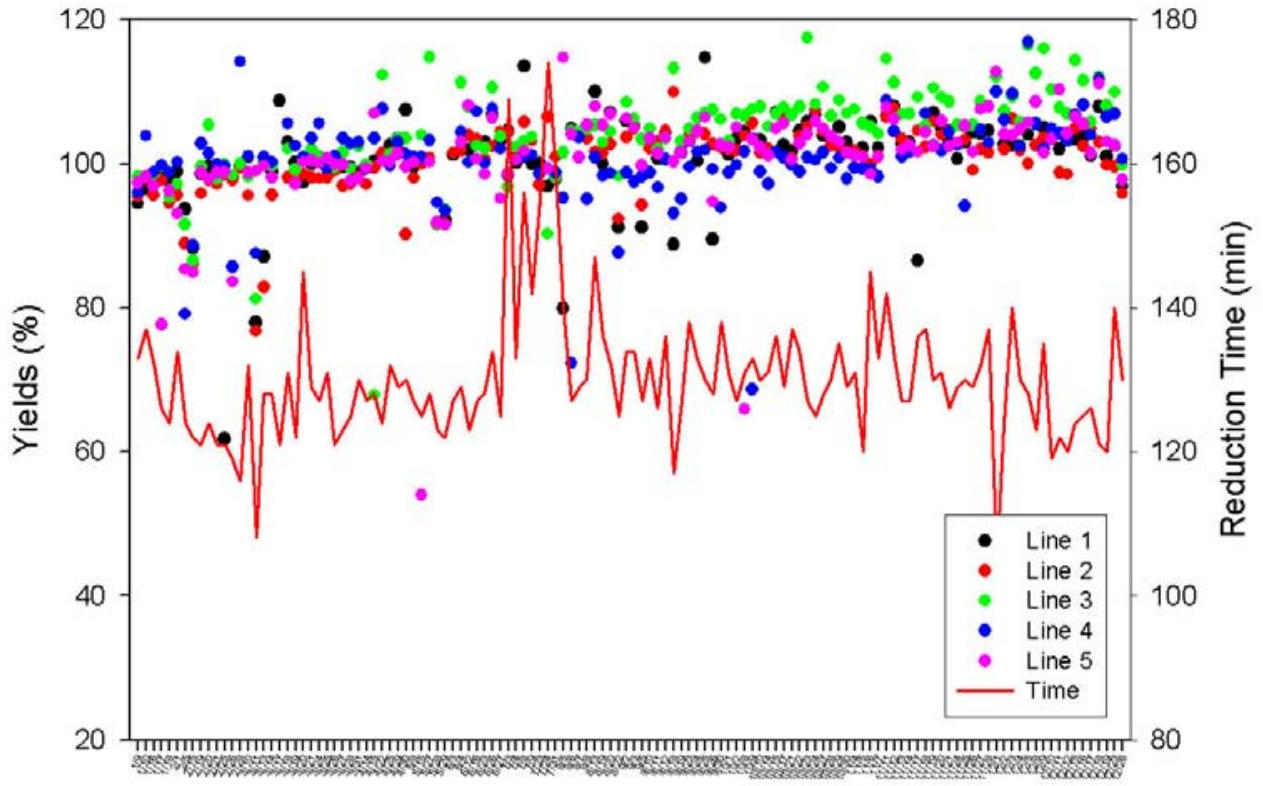

Date in 2008

(b)

Figure 3 Performance of the prototype reduction system: (a) curves of pressure and temperature change during reduction reaction; (b) reduction yield distribution in 2008. Reduction yields are overestimated by $2-3 \%$ due to pressure gauge uncertainty. 


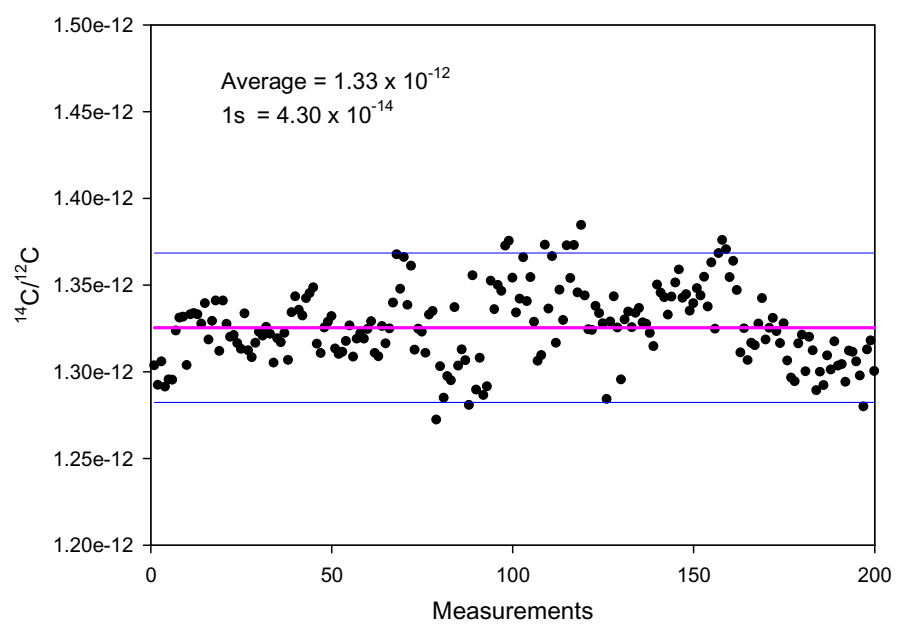

(a)

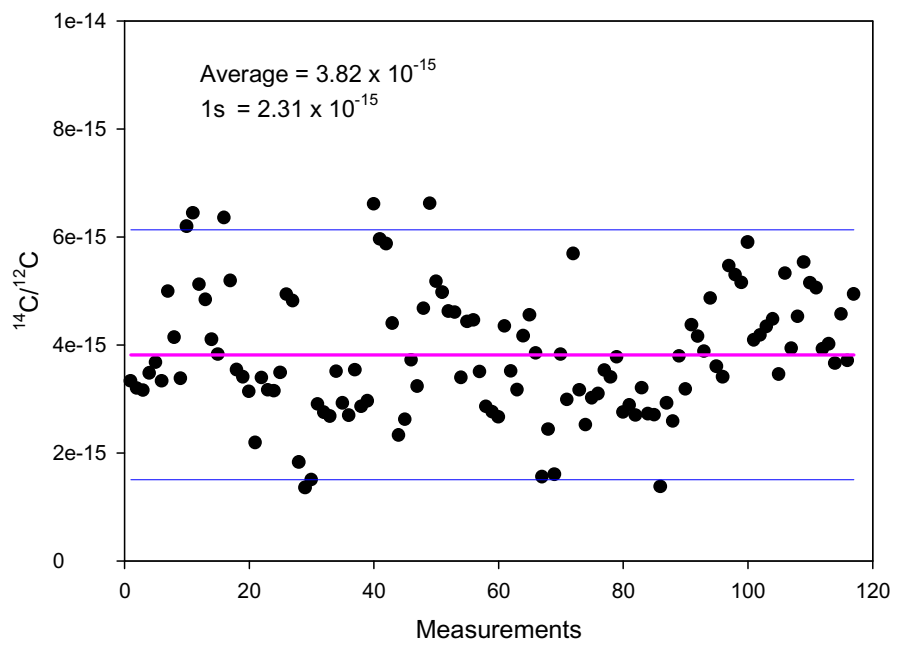

(b)

Figure 4 Variation of ${ }^{14} \mathrm{C} /{ }^{12} \mathrm{C}$ ratios of (a) NIST standard (oxalic acid II) samples and (b) blank samples treated by the prototype reduction system.

With the data obtained from operating the prototype reduction system for $1 \mathrm{yr}$, an automated 24-fold reduction system with (dimensions of $234 \mathrm{~W} \times 75 \mathrm{D} \times 160 \mathrm{H} \mathrm{cm}$ ) has been developed (Figure 5) since end of 2008. This system has basically the same structure as the prototype. The major difference is the use of pneumatic valves and air-actuated pistons to move $\mathrm{LN}_{2}$ and ethanol dewars. Heaters are run by geared motors. All the units for automatic manipulation and sensors of this new system are interfaced to a personal computer via National Instrument (NI) modules and a board. The software to control the system has been developed by NI-DAQ libraries, NI Measurement Studio ${ }^{\circledR}$ and Microsoft Visual Studio ${ }^{\circledR}$. The main screen of the software is presented in Figure 6. Displays of pressures and temperatures are centered on the screen for user convenience. The automatic process is divided into 3 parts: preheating of the catalyst, sample collection, and reduction. The reduction 
system is also divided into 2 regions, and they can be operated separately. For instance, while reduction is carried out in one region, the catalyst can be preheated in another region, depending on needs. The software also performs automatic pressure gauge calibration using $\mathrm{CO}_{2}$ gas and an additional precise and stable pressure gauge, which is calibrated regularly by the Korea Research Institute of Standard and Science (KRISS). Two turbopumps and 2 oil-less backing pumps are used to evacuate the system and typical vacuum was $8 \times 10^{-7}$ Torr at the center line.

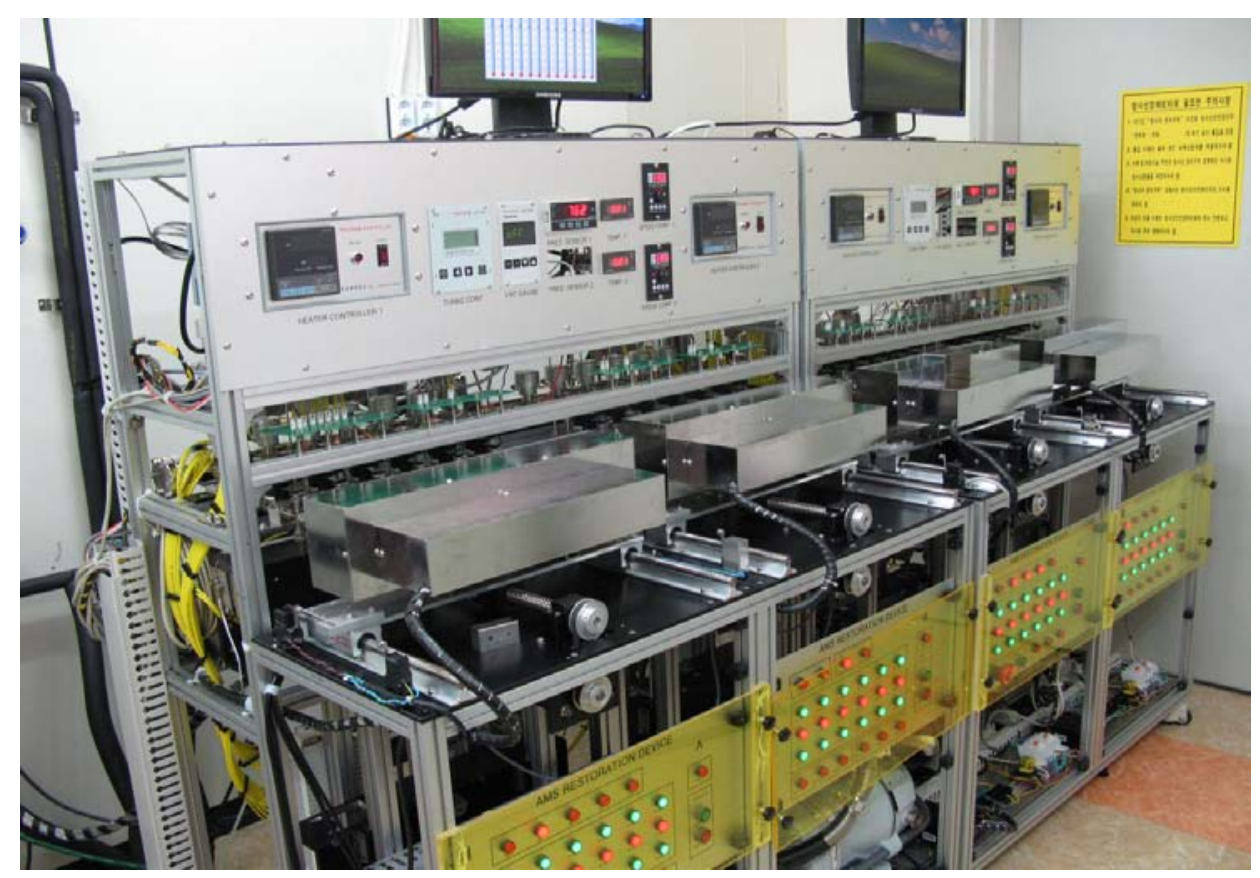

Figure 5 Overview of 24-fold automatic reduction system at KIGAM

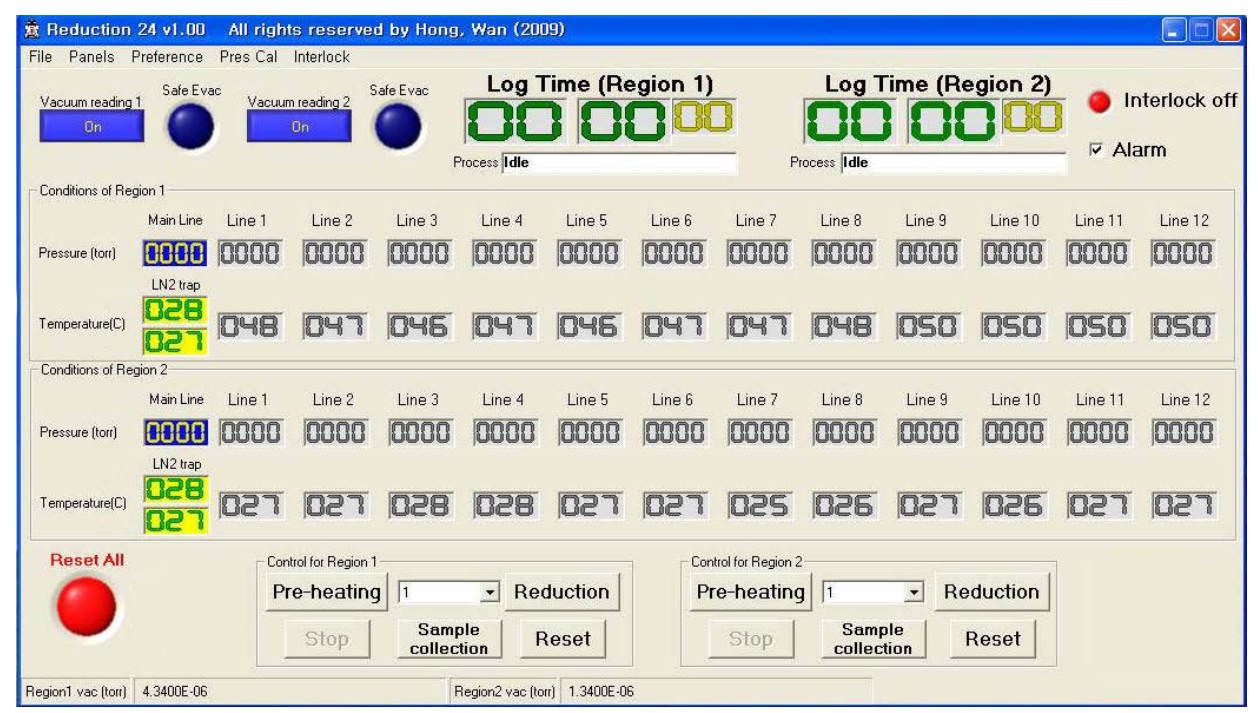

Figure 6 Main screen of the control software of 24-fold automatic reduction system 
Performance of the new reduction system is demonstrated in Table 1 and Figure 7 . The pressure of each line changes in a very similar way and the pressure drop stopped after $160 \mathrm{~min}$. The reduction time is longer than the prototype by 20 min. The reduction yield was $93.1 \%$. Figure 8 shows the reduction yields distribution of the automatic system for 64 samples. Average yield was found to be $91.6 \%$, which is slightly smaller than the prototype. However, the small standard deviation shows

Table 1 Typical performance of the automatic reduction system.

\begin{tabular}{lllllllllllll}
\hline Line & 1 & 2 & 3 & 4 & 5 & 6 & 7 & 8 & 9 & 10 & 11 & 12 \\
\hline $\mathrm{CO}_{2}$ (Torr) & 260 & 278 & 251 & 250 & 248 & 249 & 252 & 249 & 250 & 249 & 251 & 251 \\
$\mathrm{C}$ (mg) & 1.20 & 1.28 & 1.16 & 1.15 & 1.14 & 1.15 & 1.16 & 1.15 & 1.15 & 1.15 & 1.16 & 1.16 \\
$\mathrm{H}_{2}$ (Torr) & 517 & 552 & 503 & 500 & 485 & 495 & 499 & 503 & 503 & 500 & 501 & 503 \\
$\mathrm{H}_{2} / \mathrm{CO}_{2}$ & 1.99 & 1.99 & 2.00 & 2.00 & 1.96 & 1.99 & 1.98 & 2.02 & 2.01 & 2.01 & 2.00 & 2.00 \\
Final pressure & 44 & 38 & 28 & 36 & 33 & 30 & 38 & 39 & 38 & 38 & 36 & 38 \\
Graphite $^{\mathrm{b}}(\mathrm{mg})$ & 1.09 & 1.17 & 1.05 & 1.04 & 1.05 & 1.09 & 1.13 & 1.09 & 1.07 & 1.07 & 1.07 & 1.08 \\
Yield (\%) & 90.7 & 91.6 & 90.7 & 90.3 & 92.0 & 95.0 & 97.1 & 94.7 & 93.2 & 93.2 & 92.8 & 93.5 \\
\hline Line & 13 & 14 & 15 & 16 & 17 & 18 & 19 & 20 & 21 & 22 & 23 & 24 \\
\hline $\mathrm{CO}_{2}$ (Torr) & 247 & 249 & 250 & 252 & 253 & 250 & 251 & 251 & 252 & 249 & 250 & 248 \\
$\mathrm{C}$ (mg) & 1.14 & 1.15 & 1.15 & 1.16 & 1.16 & 1.15 & 1.16 & 1.16 & 1.16 & 1.15 & 1.15 & 1.14 \\
$\mathrm{H}_{2}$ (Torr) & 487 & 496 & 500 & 503 & 503 & 505 & 507 & 504 & 509 & 499 & 507 & 501 \\
$\mathrm{H}_{2} / \mathrm{CO}$ & 1.97 & 1.99 & 2.00 & 2.00 & 1.99 & 2.02 & 2.02 & 2.01 & 2.02 & 2.00 & 2.03 & 2.02 \\
Final pressure & 34 & 36 & 31 & 37 & 51 & 50 & 35 & 35 & 49 & 37 & 33 & 46 \\
$\mathrm{Graphite}$ (mg) & 1.10 & 1.12 & 1.08 & 1.10 & 0.99 & 1.08 & 1.06 & 1.08 & 1.05 & 1.09 & 1.07 & 1.06 \\
Yieldc (\%) & 96.4 & 98.1 & 94.3 & 94.7 & 85.2 & 93.5 & 91.5 & 93.5 & 90.2 & 95.4 & 92.9 & 92.7 \\
\hline
\end{tabular}

${ }^{a}$ Calculated values by $\mathrm{CO}_{2}$ pressure and the average volume of reduction regions.

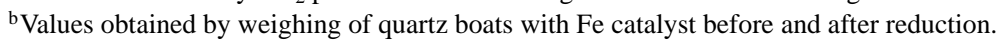

cAverage yield of the 24 lines was $93.1 \%$

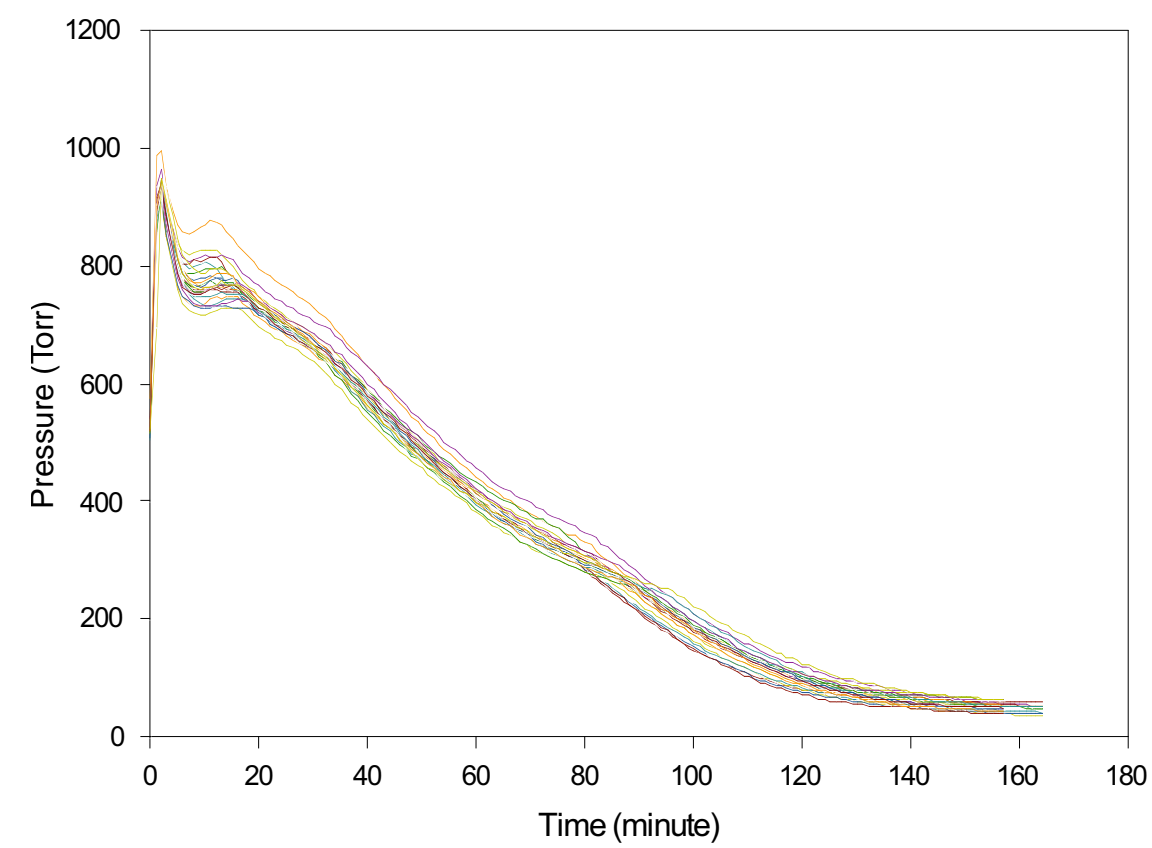

Figure 7 Curves of pressure variation during reduction reaction with automatic reduction system 
the system is very stable and confident. ${ }^{14} \mathrm{C}$ measurements were performed to evaluate the reproducibility of the system, and the results are presented in Figure 9. The average ${ }^{14} \mathrm{C} /{ }^{12} \mathrm{C}$ ratio of NIST oxalic II sample is $1.35 \times 10^{-12}$, which is close to measured value in 2008. Also, the standard deviation is very small. The blank value is $3.62 \times 10^{-15}$. The known samples, C8 from IAEA (Le Clercq et al. 1998), were treated by the automatic reduction system and measured to evaluate the accuracy of the system. Table 2 shows the results. The average activity is higher than the consensus value, $15.03 \pm 0.17 \mathrm{pMC}$. More study to solve this problem is needed for precise measurement.

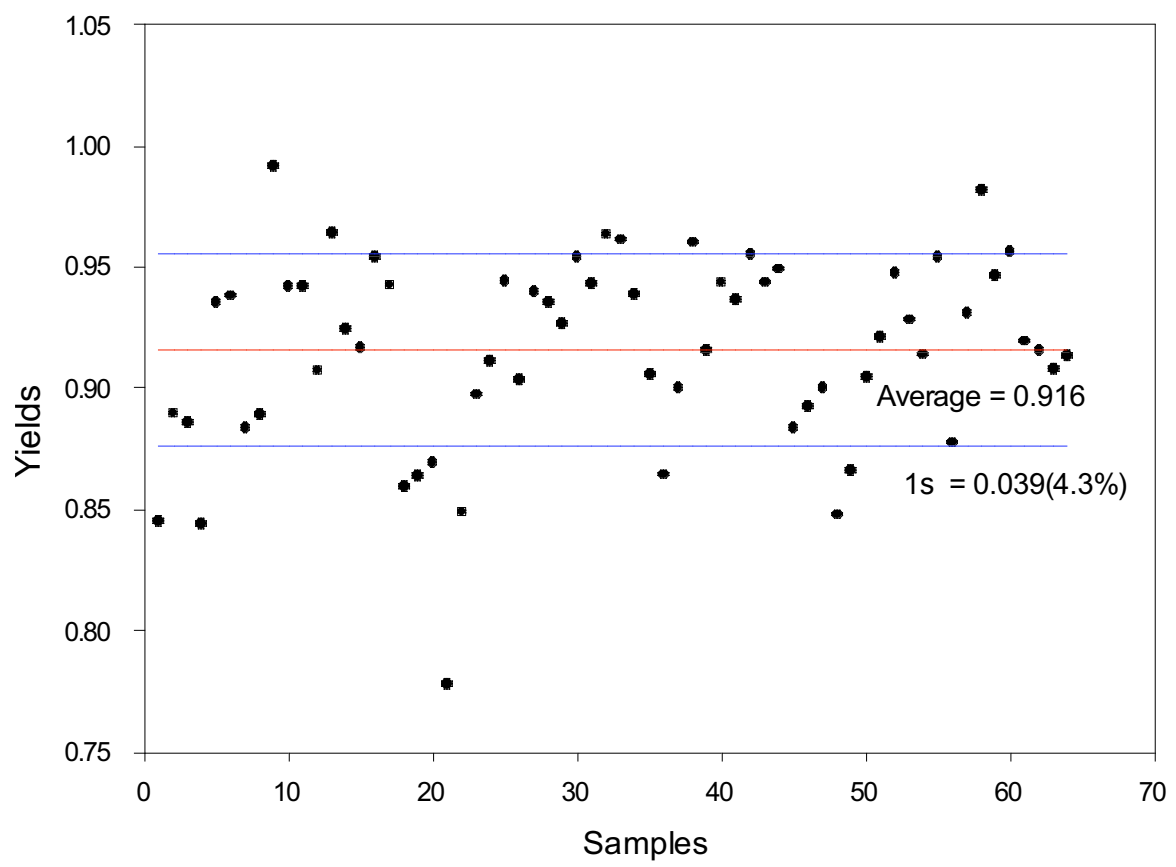

Figure 8 Reduction yield distribution of automatic reduction system. Average yield and standard deviation were $91.6 \%$ and $3.9 \%$, respectively.

Table 2 Activities of IAEA C8 reference material treated by the automatic reduction system.

\begin{tabular}{lll}
\hline Sample ID & Activity $^{\mathrm{a}}(\mathrm{pMC})$ & $1 \sigma$ \\
\hline T8C090041 & 15.58 & 0.18 \\
T8C090042 & 15.78 & 0.18 \\
T8C090045 & 16.14 & 0.19 \\
T8C090049 & 16.19 & 0.14 \\
T8C090051 & 15.66 & 0.16 \\
T8C090054 & 15.49 & 0.15 \\
T8C090065 & 15.15 & 0.14 \\
T8C090066 & 15.27 & 0.16 \\
T8C090067 & 15.17 & 0.15 \\
T8C090068 & 15.28 & 0.15 \\
\hline
\end{tabular}

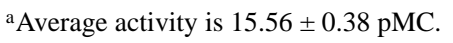




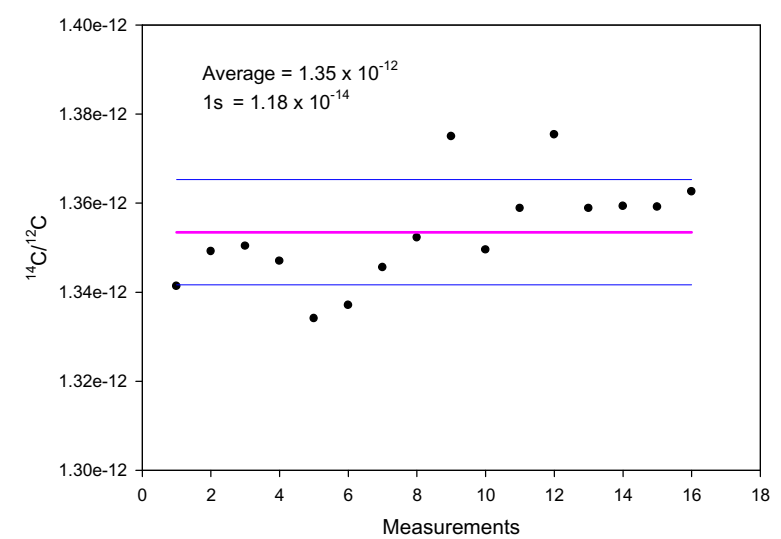

(a)

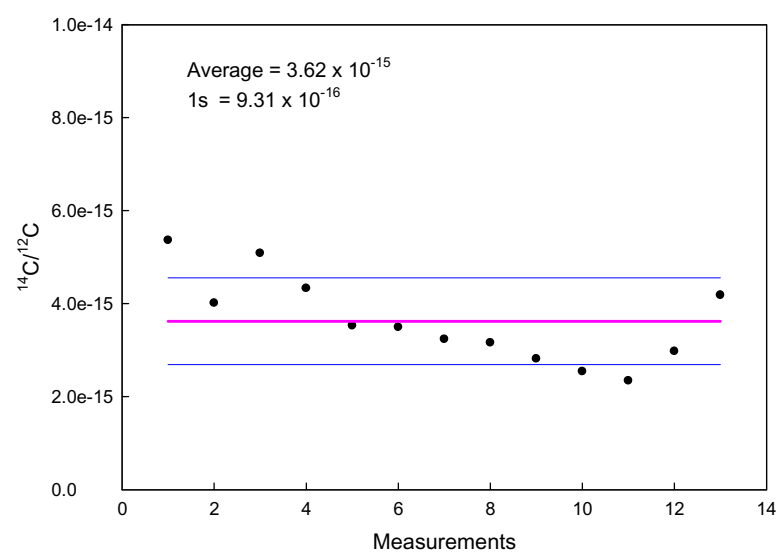

(b)

Figure 9 Variation of ${ }^{14} \mathrm{C} /{ }^{12} \mathrm{C}$ ratios of (a) NIST standard (oxalic acid II) samples and (b) blank samples treated by the automatic reduction system.

\section{CONCLUSION}

Sample preparation procedures for various kinds of samples for ${ }^{14} \mathrm{C}$ dating have been established at KIGAM AMS laboratory. We have performed ${ }^{14} \mathrm{C}$ dating since the beginning of 2008, and the overall sample preparation procedures at KIGAM seem to have produced reliable results so far, though several minor modifications such as fine adjustments of acid concentration of ABA and reaction time were needed. The database of results from chemistry, reduction, and AMS measurement for each sample play very important roles in the quality control of age because it makes the inquiry of the sample history very easy. The database also provides a table with several important interim results of the treatment steps for final revision meeting before reporting the sample ages to the customers. We measured more than 500 commercial samples and 500 samples for our own purposes in 2008 using the prototype reduction system. Our throughput is limited by insufficient manpower. As the 24-fold automatic reduction system started routine analysis just recently, it is expected that the throughput could be expanded to as many as 2000 commercial samples per year with only 4 staff members. For the automatic routine work, research on the enhancement of the system accuracy is still being conducted. 


\section{ACKNOWLEDGMENTS}

This work has been supported by the General Research Project funded by the Korea Research Council for Industrial Science \& Technology and the Ministry of Knowledge Economy.

\section{REFERENCES}

Aerts-Bijma AT, Meijer HAJ, van der Plicht J. 1997. AMS sample handling in Groningen. Nuclear Instruments and Methods in Physics Research B 123(1-4): 221-5.

Hong W, Park JH, Sung KS, Woo HJ, Kim JK, Choi HW, Kim GD. 2010. A new 1MV AMS facility at KIGAM. Radiocarbon 52(2-3):243-51.

Hua Q, Barbetti M, Jacobsen GE, Zoppi U, Lawson EM. 2000. Bomb radiocarbon in annual tree rings from Thailand and Australia. Nuclear Instruments and Methods in Physics Research B 172(1-4):359-65.

Jacobi RM, Higham TFG, Bronk Ramsey C. 2006. AMS radiocarbon dating of Middle and Upper Palaeolithic bone in the British Isles: improved reliability using ultrafiltration. Journal of Quaternary Science 21(5): 557-73.

Kristiansen SM, Dalsgaard K, Holst MK, Aaby B, Heinemeier J. 2003. Dating of prehistoric burial mounds by ${ }^{14} \mathrm{C}$ analysis of soil organic matter fractions. Radiocarbon 45(1):101-12.

Le Clercq M, van der Plicht J, Gröning M. 1998. New ${ }^{14} \mathrm{C}$ reference materials with activities of 15 and 50 pMC. Radiocarbon 40(1):295-7.

Lee C, Kim JC, Park JH, Kim IC, Kang J, Cheoun MK, Choi SY, Kim YD, Moon CB. 2000. Progress in sample preparation system for the Seoul National University AMS facility. Nuclear Instruments and Methods in Physics Research B 172(1-4):454-7.

Park JH, Hong W, Woo HJ, Choi HW, Kim JK, Kim GD. 2010. Simple treatment method of iron and calcium carbonate samples. Radiocarbon 52(2-3):1295-300.

Park JY, Hong W, Park JH. 2009. Development of humic acid extraction method in soil and sediment using ultrasonic for ${ }^{14} \mathrm{C}$ dating. Analytical Science \& Technology 22(2):136-40. In Korean with English abstract.

Sveinbjörnsdóttir Á, Heinemeier J, Anórsson S. 1995. Origin of ${ }^{14} \mathrm{C}$ in Icelandic groundwater. Radiocarbon 37(2):551-65.

Tisnérat-Laborde N, Poupeau JJ, Tannau JF, Paterne M. 2001. Development of a semi-automated system for routine preparation of carbonate samples. Radiocarbon 43(2A):299-304. 